\title{
Adsorption of syndiotactic and isotactic poly(2-vinylpyridine 1-oxide) on quartz surface
}

\author{
M. DOBREVA and N. DANCHEVA \\ Centre of Hygiene, Sofia, Bulgaria \\ P. F. HOLT \\ Department of Chemistry, University of Reading
}

\begin{abstract}
Dobreva, M., Dancheva, N., and Holt, P. F. (1975). British Journal of Industrial Medicine, 32, 224-227. Adsorption of syndiotactic and isotactic poly(2-vinylpyridine 1-oxide) on quartz surface. Poly(2-vinylpyridine 1-oxide) inhibits the cytotoxic effects of quartz in cell cultures but the syndiotactic polymer behaves differently from the isotactic and atactic polymers. In each case approximately $1.0 \mathrm{mg} / \mathrm{m}^{2}$ of the polymer represents the adsorption maximum. No difference has been found between the adsorption isotherms of the stereoisomeric polymers or the stability of the adsorbed layers. The layers are not removed by repeated washing. The observations do not support the theory that the poly(2-vinylpyridine 1-oxide) is active because it coats the quartz surface.
\end{abstract}

The protective action of poly(2-vinylpyridine 1-oxide) (PVNO) against quartz fibrogenicity in animals (Schlipköter and Brockhaus, 1961) and quartz cytotoxicity in cell cultures (Beck, Bruch, and Brockhaus, 1963) is established and has been confirmed by many workers. Some of the evidence has been reviewed by Holt (1971). The effect has been shown both when the dust is pretreated with the polymer and when animals that inhaled or were injected with quartz dust were given injections of PVNO. In macrophage cultures, activity has been proved both by pretreating the dust and by pretreating the cells.

Studies of polymers with modified structures suggest that the protective activity requires the $\mathrm{N}$ oxide grouping and a high molecular weight polymer. Three alternative hypotheses have been proposed to account for the effect: $(a)$ the protective effect results from the formation of an adsorbed polymer layer on the quartz surface preventing contact with the biological substrate, (b) PVNO interacts with components of the cell system leading to a stabiliza- tion of the cell or lysosomal membrane, and (c) PVNO forms a complex with monosilicic acid formed by solution of silica in the cell. Some factors can be adduced to support each of these theories. Adsorption of PVNO on quartz from an aqueous substrate has been proved (Schlipköter and Brockhaus, 1961) and has been studied by Antweiler and Djie (1971) who showed that PVNO is strongly adsorbed and will replace protein that was previously adsorbed. The adsorbed layer is partially removed at $\mathrm{pH} 10-12$ but not by continuous washing with water, tyrode solution, or aqueous solutions between $\mathrm{pH} 2$ and 8 (hydrochloric acid and sodium hydroxide). Adsorption probably involves $\mathrm{H}$-bond formation between $\mathrm{N}$-oxide groups and $\mathrm{OH}$-groups of the silica surface.

Isotactic and syndiotactic PVNO are identical polymers except that the arrangement of the pyridine rings along the polyvinyl chain differs. In the isotactic polymer all the pyridine rings lie on one side of the extended chain, but in the syndiotactic polymer the rings lie alternately to the left and right. The atactic 
polymer has a random arrangement. Isotactic and syndiotactic PVNO (tacticity confirmed by nuclear magnetic resonance and viscosity) behave differently towards monosilicic acid (Holt and Lindsay, 1969). Holt, Lindsay, and Beck (1970) examined the effects of atactic, isotactic, and syndiotactic PVNO and a number of variously oriented methyl derivatives on the cytotoxicity of quartz to macrophages in culture. The isotactic polymer proved to be as active in preventing the cytotoxic effects of quartz as was the atactic polymer when the cells were pretreated, but it was inactive when the quartz was pretreated. Conversely, the syndiotactic PVNO was active when the quartz was pretreated but not when the cells were pretreated. The effect is not a simple one, however, since some methyl derivatives of PVNO increase the cytotoxicity of quartz even though they are not themselves cytotoxic. This effect may be due to the removal by those polymers of an adsorbed layer of silicic acid which is normally present on a quartz surface (Holt and King, 1955). Sodium hydroxide and hydrofluoric acid which remove the layer also increase the fibrogenic activity of quartz.

If PVNO counteracts the cytotoxicity of quartz because it forms a layer on the quartz surface, the observed difference between the effects of the stereospecific forms of PVNO would imply a difference in the adsorption isotherms of the two forms, or a difference in the desorption when coated quartz is extracted with an aqueous solvent. The aim of this work was to determine whether the syndiotactic and isotactic forms of PVNO behave differently in this respect.

\section{Materials and methods}

Two types of quartz dust were used. Each had the following characteristics:

Quartz A, specific surface $6.7 \mathrm{~m}^{2} / \mathrm{g}$; particle size distribution $<1 \mu \mathrm{m}, 90 \% ; 1-3 \mu \mathrm{m}, 9 \%, 3-5 \mu \mathrm{m}, 0.2 \%$.

Quartz B, specific surface $1.5 \mathrm{~m}^{2} / \mathrm{g}$; particle size distribution: $<1 \mu \mathrm{m}, 60 \% ; 1-3 \mu \mathrm{m}, 30.7 \% ; 3-5 \mu \mathrm{m}, 5.0 \%$; $5-10 \mu \mathrm{m}, 3 \cdot 8 \% ; 10-20 \mu \mathrm{m}, 0 \cdot 5 \%$.

Polymer solution $\left(15 \mathrm{~cm}^{3}\right)$ in various concentrations between 50 and $800 \mu \mathrm{g} / \mathrm{cm}^{3}$ in saline was added to portions of $A(0.5 \mathrm{~g})$ and $B(1.0 \mathrm{~g})$. The suspensions were dispersed at ultrasonic frequency $(22 \mathrm{kHz})$ for 2 min then centrifuged at $3000 \mathrm{revs} / \mathrm{min}$ for $20 \mathrm{~min}$. The residual polymer in the supernatant fluid was estimated spectrophotometrically at $\lambda_{\max }=260 \mathrm{~nm}$. The amount of polymer adsorbed was taken to be the difference between the PVNO in the original solution and in the supernatant.

The treated dusts were washed several times in water until the polymer could no longer be detected in the washings, and then they were dried at $60^{\circ} \mathrm{C}$. Subsequent adsorption experiments similar to the first were then made on the washed dusts. If the quartz retained a complete monolayer of PVNO after washing, negligible adsorption of PVNO would be expected subsequently.
TABLE 1

PVNO (mg) Adsorbed on Quartz A (1 g) AFTer EQUILIBRATION WITH VARIOUS CONCENTRATIONS OF Atactic PVNO

\begin{tabular}{|c|c|c|c|c|c|c|c|}
\hline$P V N O$ & & & & $m g$ & & & \\
\hline $\begin{array}{l}\text { Added } \\
\text { Adsorbed after } \\
\text { equilibration } \\
\text { First } \\
\text { Second } \\
\text { Third } \\
\text { Fourth }\end{array}$ & $\begin{array}{l}4 \cdot 5 \\
\\
4 \cdot 4 \\
3 \cdot 4 \\
0 \cdot 3 \\
0\end{array}$ & $\begin{array}{l}7 \cdot 2 \\
\\
5 \cdot 2 \\
1 \cdot 8 \\
0 \cdot 3 \\
0\end{array}$ & $\begin{array}{l}9 \cdot 0 \\
\\
5 \cdot 0 \\
2 \cdot 0 \\
0 \cdot 4 \\
0\end{array}$ & $\begin{array}{l}13 \cdot 9 \\
\\
7 \cdot 1 \\
0 \cdot 4 \\
0\end{array}$ & $\begin{array}{r}14 \cdot 7 \\
\\
6.9 \\
1.0 \\
0 \cdot 1\end{array}$ & $\begin{array}{l}18 \cdot 0 \\
\\
7 \cdot 1 \\
0 \cdot 8 \\
0\end{array}$ & $\begin{array}{l}24 \cdot 0 \\
\\
6 \cdot 9 \\
0 \cdot 3 \\
0\end{array}$ \\
\hline Total & $8 \cdot 1$ & $7 \cdot 3$ & $7 \cdot 4$ & $7 \cdot 5$ & $8 \cdot 0$ & $7 \cdot 9$ & $7 \cdot 2$ \\
\hline
\end{tabular}

\section{Results and discussion}

If quartz $\mathrm{A}$ is equilibrated with more than about 15 $\mathrm{mg}$ atactic PVNO per $\mathrm{g}$ dust and is then washed and dried the amount of PVNO subsequently adsorbed from solution is small (Table 1), indicating that most of the quartz surface is covered during the first application of PVNO and that little is removed from the surface by washing. With smaller quantities of PVNO, the surface is incompletely covered by a single equilibration but the total amounts adsorbed during all the equilibrations approximate to the value obtained when more than $15 \mathrm{mg}$ PVNO per $\mathrm{g}$ of quartz is used. The isotactic polymer behaved essentially in the same way (Table 2). When the quartz is equilibrated with atactic PVNO the amount of polymer adsorbed after $1 \mathrm{hr}(6.9 \mathrm{mg})$ is slightly smaller than that adsorbed if $24 \mathrm{hr}$ are allowed for equilibration (Table 3). When the quartz is subsequently equilibrated with PVNO more polymer is adsorbed by the quartz with the lighter coating, so the total adsorption is slightly higher if $1 \mathrm{hr}$ is allowed for the initial equilibration. This is probably explained by the fact that each polymer chain is at first attached to the quartz surface at only a few points

TABLE 2

PVNO (mg) Adsorbed by Quartz A (1 g) AFTer EQUILIBRATION WITH VARIOUS CONCENTRATIONS OF ISOTACTIC PVNO

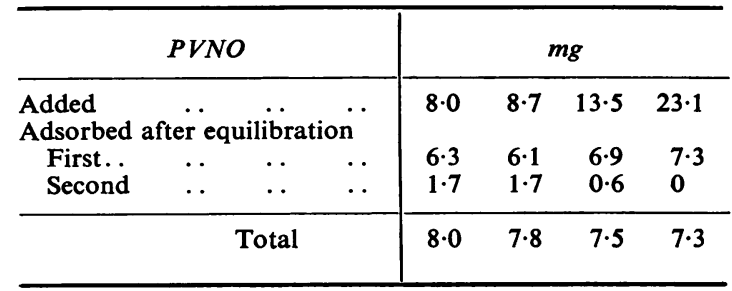


TABLE 3

PVNO (mg) ADSORBED AFTER 1 AND 24 HR Equilibration of Atactic PVNO (14.1 mg) With QuARTZ A (1 g)

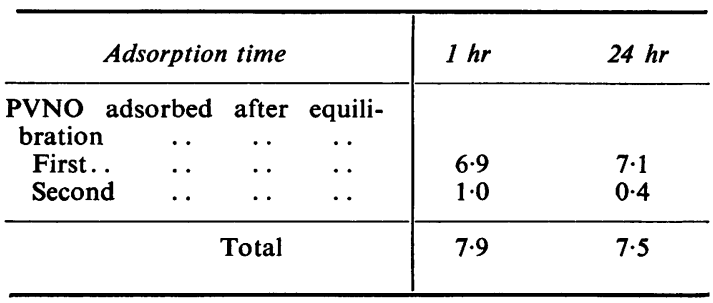

and gives a loose random and thicker coating. Subsequently the chain becomes bound at more points, is closer to the surface, more regularly arranged, and consequently gives a thinner layer. However, the longer period allows better final packing and the surface is more nearly completely covered.

Adsorption isotherms of atactic, isotactic, and syndiotactic PVNO on Quartz B are indistinguishable (Fig. 1). The maximum PVNO adsorbed is about 1.2 $\mathrm{mg} / \mathrm{g}$ quartz, equivalent to $0.8 \mathrm{mg} / \mathrm{m}^{2}$ surface. The adsorption isotherms of atactic and isotactic PVNO on Quartz A (Fig. 2) are again indistinguishable. The maximum PVNO adsorbed is about $7 \mathrm{mg} / \mathrm{g}$ quartz, equivalent to about $1.0 \mathrm{mg} / \mathrm{m}^{2}$ surface. These iso-

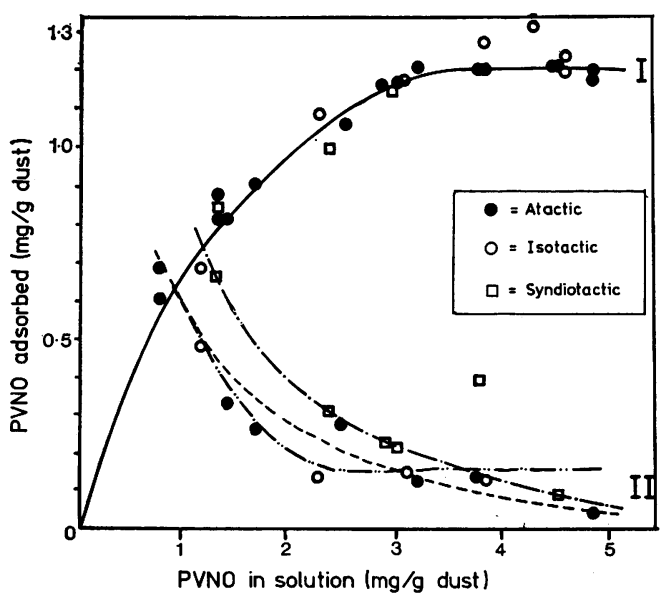

FIG. 1. Adsorption isotherms of atactic ( $O$ ), isotactic $(O)$, and syndiotactic ( $\square$ ) PVNO on quartz dust B (surface area $1.5 \mathrm{~m}^{2} / \mathrm{g}$ ). I. Initial experiment. II. Adsorption on the quartz samples used in the initial experiment after they had been washed and dried. The small amount of PVNO adsorbed on the samples equilibrated with more than about $3.5 \mathrm{mg} / \mathrm{g}$ dust indicates that a complete monolayer of polymer was formed in the first equilibration.

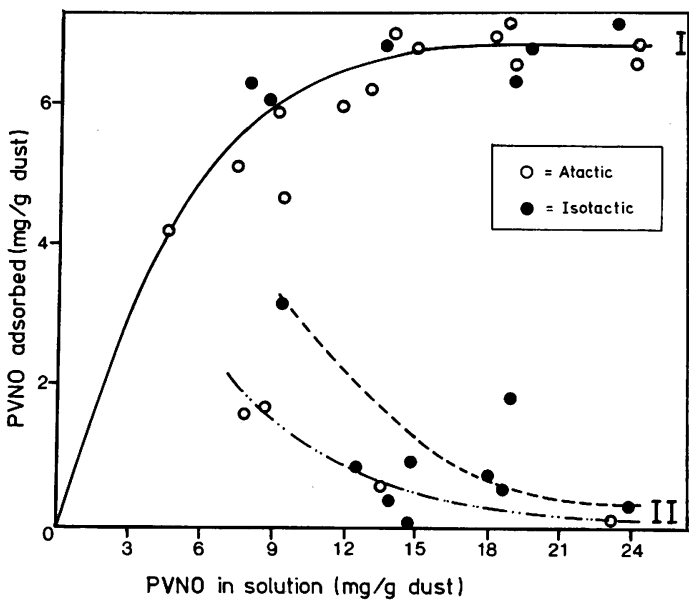

FIG. 2. Adsorption isotherms of atactic and isotactic PVNO on quartz dust A (surface area $6.7 \mathrm{~m}^{2} / \mathrm{g}$ ). I. Initial experiment. II. Adsorption on quartz samples used in the initial experiment after they had been washed and dried. Again very little PVNO was adsorbed on samples completely coated with a monolayer in the first equilibration (i.e. equilibrated with more than $15 \mathrm{mg} / \mathrm{g}$ dust).

therms suggest that the quartz surface behaves similarly to the three stereoisomeric polymers and that each isomer gives a monolayer on the silica surface. Presumably the polymer chains are attached by $\mathrm{H}$-bonds formed between the oxygen of the Noxide groups and the $-\mathrm{OH}$ groups of the silica surface. Interaction of silicic acid with $\mathrm{N}$-oxide groups in monolayers of alkylpyridine oxides has been used as a model system to study this type of H-bonding (Holt and Nasrallah, 1969).

The curves II in Figs. 1 and 2 show that when the quartz is coated with $1.0 \mathrm{mg} \mathrm{PVNO} / \mathrm{m}^{2}$ quartz surface, washed, dried, and equilibrated with more PVNO, very little extra polymer is adsorbed, confirming that little polymer is removed by washing. If less than $1.0 \mathrm{mg}$ is initially adsorbed, the total amount adsorbed is slightly higher, probably because the adsorbed layer is less stable.

There is little doubt that PVNO protects cells in culture and the intact lung from pathogenic effects of silica. Theories regarding the mechanism of action of the PVNO reviewed by Holt (1971) involve the coating of the quartz surface, interaction with silicic acid formed from the quartz, or stabilization of cellular or subcellular membranes. Since the stereoisomeric forms of PVNO have different effects on the cytotoxicity of quartz in cell cultures but are indistinguishable so far as their adsorption on quartz is concerned, it is improbable that their activity is due to surface coating of the quartz. This observation is supported by evidence previously presented that 
some other polymers that can hydrogen bond to a quartz surface are inactive against the pathogenic activity of quartz (Schlipköter and Brockhaus, 1963; Djie, 1970; Antweiler and Djie, 1971), that PVNO is more effective when injected into an animal than when used to pre-treat quartz, and that PVNO counteracts the effects of certain other toxins, such as tetrachloromethane (Otto, 1967).

\section{References}

Antweiler, H. and Djie, T. T. (1971). Adsorption of poly-2-vinylpyridine-N-oxide on quartz particles. Beiträge zur Silikose-Forschung (Pneumokoniosis), 23, 63-90.

Beck, E. G., Bruch, J., and Brockhaus, A. (1963). The influence of polyvinylpyridine-N-oxide (P 204) on the cytotoxic action of quartz on mouse fibroblasts (Strain L). Zeitschrift für Zellforschung, 59, 568-576.

Djie, T. T. (1970). Untersuchungen zur Adsorption von Poly-2-vinyl pyridin-N-oxid auf Quartzteilchen. Dissertation, Düsseldorf.

Holt, P. F. (1971). Poly(vinylpyridine oxides) in pneumoconiosis research. British Journal of Industrial Medicine, 28, 72-77.

- and King, D. T. (1955). The chemistry of silica surfaces. Journal of the Chemical Society, 773-779.

- and Lindsay, H. (1969). Isotactic and syndiotactic poly (2-vinylpyridine 1-oxide) and poly (2-vinylpyridine oxide-co-2-n-propenylpyridine oxide): nuclear magnetic resonance and ultraviolet spectra, viscosities and reactions with silicic acids. Journal of the Chemical Society, Section C, 1012-1015.

- and Beck, E. G. (1970). Some derivatives of polyvinylpyridine 1-oxides and their effect on the cytotoxicity of quartz in macrophage cultures. British Journal of Pharmacology, 38, 192-201.

— and Nasrallah, E. T. (1969). Alkylpyridine oxide monolayers as analogues of poly(vinylpyridine oxides): a study of the interaction of heptadecylpyridine oxides with monosilicic acid. Journal of the Chemical Society, Section C, 823-826.

Otto, M. (1967). Der Einfluss von PVNO (P 204) auf die Alveolarmakrophagen der Rate nach Quarzinhalation - eine elektronenmikroskopische Untersuchung. Dissertation, Düsseldorf.

Schlipköter, H. W. and Brockhaus, A. (1961). Die Hemmung der experimentellen Silikose durch subcutane Verabreichung von Polyvinylpyridin-N-Oxyd. Klinische Wochenschrift, 39, 1182-1188.

_ and - (1963). Untersuchungen zur Beeinflussung der Silikose. In Fortschritte der Staublungenforschung, edited by H. Reploh and W. Klosterkötter, pp 397413. Niederrheinische Druckerei, Dinslaken.

Received for publication 20 February 1975. Accepted for publication 7 April 1975 . 